\title{
Immunoglobulin and complement receptor-bearing cells in cultures of mouse decidual tissue
}

\author{
Katrina J. Kirkwood \\ Reproductive Immunology Group, Department of Pathology, The Medical School, \\ University Walk, Bristol BS8 1TD, U.K.
}

\begin{abstract}
Summary. Cells disaggregated from decidual tissue of the pregnant mouse were cultured overnight and examined in erythrocyte-antibody rosetting assays for the presence of cell surface receptors for the $\mathrm{Fc}$ region of immunoglobulin. Fc receptor-bearing cells were present from Day 4 post coitum (Day $1=$ day of mating) as an increasing proportion of the total number of cells in the cultures, although the precise proportion showed considerable strain-dependent variation. In a similar assay, complement receptor-bearing cells were not detected in cultures of decidual tissue until 14-15 days of pregnancy. The presence of Fc receptor-bearing cells in the decidua supports the suggestion that this tissue may have a role in the immunological interactions between the mother and her antigenically alien embryo.
\end{abstract}

\section{Introduction}

The response of the uterine mucosa to the presence of the embryo in many mammalian species results in the transformation of the stromal cells into the characteristic decidual tissue. Although it has long been recognized that decidual tissue is involved in the nutrition of the embryo (Finn, 1971), it has more recently been postulated that it may also have an important role in maternal-fetal immunological interactions (Beer \& Billingham, 1974, 1976; Hetherington, 1971; Hetherington \& Humber, 1975).

Cells bearing Ia antigens have been identified in the decidua basalis of mouse conceptuses at 14-16 days post coitum (Jenkinson \& Searle, 1979). Immunoglobulin binding cells have been found amongst early mouse decidual cells (Bernard, Scheid, Ripoche \& Bennett, 1978) and Fc receptor-bearing cells (FcR cells) have been identified in the metrial gland of the pregnant rat uterus (Bray, Stewart \& Craggs, 1978). Both Ia antigens and Fc receptors are frequently associated with cells having immunological functions, such as lymphocytes and macrophages. FcR cells are known to be mediators of antibody-dependent cytotoxicity (Kerbel \& Davies, 1974; Dickler, 1976) and $F c$ receptors are also involved in the inhibition of a variety of immunological effects, such as responsiveness to B cell mitogens (Ryan, Arbeit, Dickler \& Henkart, 1975) and the generation of plaque-forming cells (La Via \& La Via, 1978). Other FcR cells appear to have suppressor cell activity (Masuda et al., 1978; Yodoi, Takabayashi \& Masuda, 1978; Neauport-Sautes \& Rabourdin-Combe, 1979). Many immunologically active cells also bear receptors for components of complement. Such receptors may be important in the presentation of antigen to lymphocytes, in attachment and ingestion of appropriately opsonized particles and may have a variety of effects in activating macrophages (McConnell \& Lachmann, 1977; Bar-Shavit, Raz \& Goldman, 1979).

In view of the possible immunological importance of the decidua and the potential significance of immunologically active cells at this site, a more detailed study of the ontogeny of 
the immunoglobulin-binding cell population of the decidua was carried out in mice of different strains mated in various combinations and the specificity of the receptors was defined. Preliminary attempts were also made to identify complement-receptor bearing cells amongst the decidual cells.

\section{Materials and Methods}

\section{Mice}

Mature female mice from the inbred strains CBA/H-T6, C57BL and A and from a small randomly breeding colony were caged overnight with fertile males and examined the next morning for the presence of a vaginal plug. The day of detection of the plug was taken as Day 1 of pregnancy.

\section{Tissues and cell culture}

The pregnant mice were killed on Days 3-15 post coitum (p.c.) by ether anaesthesia. To prepare 3-6 day p.c. 'decidual' tissue for culture it was necessary to use the whole uterus and as a control for possible contributions from non-decidual elements, uteri of virgin mice were treated in the same way. At later stages of gestation the uterus was cut open along the anti-mesometrial line and the conceptuses with their surrounding decidual tissue were removed. The decidual tissue, the extent of which varied with stage of gestation, was peeled away from the underlying embryonic tissues with watchmaker's forceps. All the decidual tissue from one 7-15-day pregnant female or the whole uterus from virgin and 3-6-day pregnant females was minced, washed once in phosphate-buffered saline (Dulbecco A and B; Oxoid, Basingstoke, U.K.) (DPBS) and incubated in $0.05 \%$ trypsin in DPBS at $37^{\circ} \mathrm{C}$ for $30 \mathrm{~min}$ with periodic agitation. The mixture was pipetted vigorously, filtered through steel gauze, centrifuged at $1000 \mathrm{~g}$, washed once and resuspended in culture medium (RPMI-1640) (Gibco-Biocult, Glasgow, U.K.) with added $10 \%$ fetal calf serum, $0.2 \%$ sodium bicarbonate, penicillin and streptomycin). Aliquots $(0.4 \mathrm{ml})$ of cell suspension were placed in pairs of MIF wells cut from migration plates (Sterilin Ltd, Middlesex, U.K.) and were kept overnight in sterile Petri dishes in moist, air-tight boxes gassed with $5 \% \mathrm{CO}_{2}$ in air.

\section{Serum}

An antiserum to sheep red cells (SRC) was prepared by injecting mice intraperitoneally with $0.2 \mathrm{ml}$ washed SRC weekly for 6 weeks. Animals were bled out 7 days after the last injection. A separate batch of this serum was used for the preparation of the $F\left(a b^{\prime}\right)_{2}$ immunoglobulin fraction. The immunoglobulins were precipitated with ammonium sulphate and separated by DEAE cellulose-ion exchange chromatography. The IgG fraction was subjected to pepsin (Sigma) digestion overnight and the $\mathrm{F}\left(\mathrm{ab}^{\prime}\right)_{2}$ fraction was separated from the digest on a Sephadex G200 column. An IgM-rich serum was prepared by injecting a similar amount of SRC intravenously and bleeding out the animals 7 days later. The IgM was purified by ammonium sulphate precipitation of the immunoglobulins and fractionation of the re-solubilized immunoglobulins on a Sephadex G200 column. Haemagglutination and immunoelectrophoresis tests were carried out on the IgM preparations to ensure that the functional activity was intact and that they were uncontaminated.

\section{Rosette assay}

Cultured decidual cells were assessed for the possession of $\mathrm{Fc}$ and complement $\left(\mathrm{C}^{\prime}\right)$ 
receptors by means of rosette assays (Parish \& Hayward, 1974; Elson, Jenkinson \& Billington, 1975). Indicator cells were prepared from a $2 \%$ suspension ( $\mathrm{v} / \mathrm{v})$ of fresh, washed SRC in DPBS supplemented with $0.2 \%(\mathrm{w} / \mathrm{v})$ bovine serum albumin. Appropriate dilutions of mouse anti-SRC serum or its IgM or $\mathrm{F}\left(\mathrm{ab}^{\prime}\right)_{2}$ fractions were incubated with an equal volume of SRC suspension for $1 \mathrm{~h}$ at room temperature to give EA, E-IgM and E-F $\left(\mathrm{ab}^{\prime}\right)_{2}$ indicator cells (iSRC) respectively. Fresh normal mouse serum was used as a complement source when appropriate and was incubated with E-IgM or untreated SRC for $1 \mathrm{~h}$ at room temperature. This latter procedure was an important control for the presence of natural antibodies to SRC. Haemagglutination tests were carried out to assess the titres of the serum and serum fragments. The maximum sub-haemagglutinating dilution was used in all subsequent experiments. The rosette assay was carried out by placing $0.1 \mathrm{ml}$ iSRC and $0.3 \mathrm{ml}$ DPBS with BSA in each culture well after washing the plates by immersion in warm DPBS to remove non-adherent cells. After incubation for $1 \mathrm{~h}$ at room temperature the plates were rinsed through three changes of DPBS. The numbers of rosetting and non-rosetting cells in 9 standard fields were counted microscopically and the percentage of rosetting cells was calculated. A minimum of 100 cells was counted in each case, except with tissue from virgin and 3-day p.c. mice because the small number of cells adhering to the wells made this impossible. Each experimental group consisted of independent assays on decidual tissue derived from 1-7 pregnant animals. The mean values for each group were calculated and the significance of differences between the groups was assessed by applying Student's $t$ tests, after the correction of the standard deviations with Bessel's factor for small group size.

\section{Results}

Uterus and decidua at Days $1-8$ p.c.

As shown in Table 1, few cells plated out from the uteri of virgin and 3-day p.c. female mice but amongst those that did were some rosette-forming cells (EA-RFC). At 4-5 days p.c. (at the time when blastocyst implantation occurs) many more cells plated out and large but variable numbers of rosetting cells were found. The use of mothers of different genotypes and variations in the number of implantation sites may both have contributed to this variability. A smaller total number of cells was obtained from Day- 6 uteri than from Day- 4 and -5 uteri, but all the cultures of decidual swellings from 7- and 8-day p.c. uteri became confluent. The mean number of EA-RFC in Day-6 p.c. cultures was lower than at 5, 7 or 8 days p.c. $(P<0.001)$. At $7-8$ days p.c. the mean numbers of rosetting cells were lower than in the earlier confluent cultures but were

Table 1. EA rosette formation and cell density of cultures of uteri and decidual tissue from mice in early pregnancy

\begin{tabular}{|c|c|c|c|c|}
\hline $\begin{array}{l}\text { Day of } \\
\text { pregnancy }\end{array}$ & Strain & $\begin{array}{l}\text { No. of cultures } \\
\text { reaching confluence }\end{array}$ & $\begin{array}{l}\text { Total cell no./field in } \\
\text { non-confluent cultures }\end{array}$ & $\begin{array}{c}\text { No. of } \\
\text { EA-RFC/field }\end{array}$ \\
\hline Virgin control & A & $0 / 5$ & $6 \cdot 3 \pm 5 \cdot 8$ & $2.4 \pm 3.5$ \\
\hline 3 & $2 \mathrm{C} 57 \mathrm{BL}+4 \mathrm{~A}$ & $0 / 6$ & $13 \cdot 1+8 \cdot 2$ & $5.6+4.0$ \\
\hline 4 & $2 \mathrm{~A}+2 \mathrm{~B} 10 . \mathrm{Br}$ & $3 / 4$ & 31.8 & $44.6+57.2$ \\
\hline 5 & $2 \mathrm{~A}+4 \mathrm{C} 57 \mathrm{BL} \times \mathrm{A}$ & $5 / 6$ & 32.6 & $34.7 \pm 21.5$ \\
\hline 6 & $2 \mathrm{~A} \times \mathrm{C} 57 \mathrm{BL}+8 \mathrm{~A}$ & $2 / 10$ & $24.7+15.4$ & $7.7+5.5$ \\
\hline 7 & A & $4 / 4$ & 二 & $20.6 \pm 5.9$ \\
\hline 8 & A & $7 / 7$ & - & $17.0+7.4$ \\
\hline 8 & CBA & $5 / 5$ & - & $6.8+2.2$ \\
\hline 8 & $\mathrm{CBA} \times \mathrm{C} 57 \mathrm{BL}$ & $4 / 4$ & - & $10.6+3.9$ \\
\hline 8 & Outbred & $7 / 7$ & - & $23 \cdot 1 \pm 5 \cdot 9$ \\
\hline
\end{tabular}


more consistent. This was only statistically significant when 8-day and 5-day cultures were compared $(P<0.02)$. Tissues from CBA females at Day 8 p.c., whether syngeneically or allogeneically mated, had significantly fewer EA-RFC/field than did A-strain or outbred animals $(P<0.001)$, and A-strain females also had fewer EA-RFC/field than did outbred mice $(P<0.05)$.

No rosette formation occurred with cultures of tissues of any age incubated only with washed SRC, E-IgM, E-F $\left(\mathrm{ab}^{\prime}\right)_{2}$, or when SRC sensitized with IgM and complement were used with cultures of decidua from Day- 8 females.

\section{Decidual cell cultures at Days 10-15}

The use of phase-contrast and incident light illumination revealed that the cultured cells were of two different types. Some were round cells, visible by incident and phase-contrast illumination, whilst others were flat, dendritic cells only clearly visible with phase contrast. The rosette-forming cells in these cultures were always round. The rosettes themselves were compact and round and control cultures with no rosettes showed distinctly more small round cells. The flat and round non-rosetted cells were counted separately, and morphological differences were observed between decidual cultures from different sources. Cultures from Day-10 pregnancies were normally confluent, with $>60 \%$ of the cells present being flat and non-rosetting. The proportion of flat cells decreased to $<10 \%$ over the period $10-15$ days p.c. in outbred and A-strain mice but only to about $50 \%$ in CBA mice.

The decidual tissue from each litter was pooled and no attempt was made to standardize the cell concentration before seeding the suspensions into culture wells. The variability in the number of fetuses per litter meant that there was variation between the cell density observed in equivalent cultures. However, several trends were evident (Table 2). In syngeneically mated A-strain and outbred mice the mean number of cells counted in 9 fields increased over the period examined. In Day-15 A $\times$ A females, there were more cells than at 11 days $(P<0.01), 13$ days $(P<0.001)$ or 14 days $(P<0.01)$, and in outbred mice there were significantly more cells at 14 than at 12 days p.c. $(P<0 \cdot 01)$. In contrast, in CBA mice the mean number of cells counted in 9 equivalent fields decreased with time; cultures of Day-11 tissue having significantly more cells than those of Day-13 or Day-15 tissues in CBA $\times$ CBA $(P<0.05$ in both cases) and CBA $\times$ C57BL $(P<0.05$ and $P<0.02$ respectively $)$ mice. Cultures of tissue from Day-11 CBA $\times$ CBA mice had significantly more cells than did those from Day-11 $\mathrm{A} \times \mathrm{A}$ mice $(P<0.02)$, whilst Day-14 CBA $\times$ C57BL cultures had significantly fewer cells than did those from A $\times$ C57BL mice $(P<0.05)$ and Day-15 CBA $\times$ CBA cultures had fewer cells than did Day-15 A $\times$ A cultures $(P<0.01)$. Cultures from outbred females had more cells than did those from $\mathrm{A} \times \mathrm{A}(P<0.01), \mathrm{CBA} \times \mathrm{CBA}(P<0.05)$ or CBA $\times$ C57BL $(P<0.01)$ mice at 14 days.

Table 2. Cell density in cultures of decidual tissue from mice of different strains at Days 11-15 p.c.

\begin{tabular}{|c|c|c|c|c|c|}
\hline Day p.c. & Outbred & $\mathrm{CBA} \times \mathrm{CBA}$ & $\mathrm{CBA} \times \mathrm{C} 57 \mathrm{BL}$ & $\mathbf{A} \times \mathbf{A}$ & $A \times C 57 B L$ \\
\hline 11 & $247 \cdot 5 \pm 205 \cdot 8$ & $514.7 \pm 158.1$ & $582.8 \pm 241.9$ & $159 \cdot 7 \pm 95.4$ & $325 \cdot 5 \pm 77 \cdot 1$ \\
\hline 12 & $199.8 \pm 115.0$ & $382.0 \pm 244.7$ & $303 \cdot 3 \pm 96 \cdot 2$ & $223 \cdot 3 \pm 190 \cdot 0$ & $194.5 \pm 37.5$ \\
\hline 13 & $278.4 \pm 131.0$ & $232 \cdot 3 \pm 116 \cdot 5$ & $216 \cdot 0 \pm 18 \cdot 4$ & $185 \cdot 5 \pm 77 \cdot 7$ & $118.4 \pm 61.7$ \\
\hline 14 & $696.3 \pm 427.1$ & $249.5 \pm 61.5$ & $104 \cdot 3 \pm 32 \cdot 2$ & $278.5 \pm 184.9$ & $371.0 \pm 107.5$ \\
\hline 15 & $752.0 \pm 567.7$ & $194 \cdot 3 \pm 88 \cdot 5$ & $100 \cdot 4 \pm 31.9$ & $659.2 \pm 313.8$ & 798 \\
\hline
\end{tabular}

Values are mean \pm s.d. for 9 fields.

The proportion of EA-RFC varied with strain in the same way as observed at 8 days p.c. (Table 3). Outbred mice had a significantly greater percentage of EA-RFC than did 
allogeneically or syngeneically mated CBA mice at $12-15$ days p.c. $(P<0 \cdot 01$, at least $)$ or allogeneically mated A-strain mice at 12 days p.c. $(P<0.002)$. At 14 and 15 days p.c. there was no significant difference between the proportion of rosetting cells in outbred or $\mathrm{A}$-strain females, and at 13-15 days p.c. the percentage of EA-RFC in A-strain females became significantly greater than in the equivalent CBA mice $(P<0.001$ for syngeneically mated females, and $P<0.05$ and $P<0.002$ for allogeneically mated females at Days 13 and 14 respectively).

Table 3. Proportions of cells forming EA rosettes in cultures of decidual tissue from mice of different strains at Days 10-15 p.c.

\begin{tabular}{|c|c|c|c|c|c|}
\hline \multirow[b]{2}{*}{ Day p.c. } & \multicolumn{5}{|c|}{ Mean \pm s.d. \% of total cells forming EA rosettes (no. of animals tested)* } \\
\hline & Outbred & $\mathrm{CBA} \times \mathrm{CBA}$ & $\mathrm{CBA} \times \mathrm{C} 57 \mathrm{BL}$ & $\mathbf{A} \times \mathbf{A}$ & $\mathrm{A} \times \mathrm{C} 57 \mathrm{BL}$ \\
\hline 10 & (1) & - & - & $17.5 \pm 10.9(5)$ & - \\
\hline 11 & $54.5 \pm 31.8(2)$ & $7 \cdot 0 \pm 4.0(3)$ & $7 \cdot 5 \pm 1 \cdot 9(4)$ & $31.0 \pm 20 \cdot 0(3)$ & $34 \cdot 5 \pm 6 \cdot 4(2)$ \\
\hline 12 & $62.6 \pm 14.8(5)$ & $2 \cdot 5 \pm 2 \cdot 1(2)$ & $14 \cdot 0 \pm 14 \cdot 1(2)$ & $37.3 \pm 31.8(4)$ & $25.5 \pm 5.0(2)$ \\
\hline 13 & $47.2 \pm 20.8(5)$ & $1.7 \pm 1.5(3)$ & $2.0 \pm 1.4(2)$ & $42.0 \pm 10.2(7)$ & $30.5 \pm 10.6(2)$ \\
\hline 14 & $69.8 \pm 19.6(6)$ & $1.5 \pm 0.7(2)$ & $11.0 \pm 2.8(2)$ & $60.9 \pm 18.6(7)$ & $71.5 \pm 2.1(2)$ \\
\hline 15 & $92.0 \pm 1.0(3)$ & $34.0 \pm 19 \cdot 0(3)$ & $9 \cdot 5 \pm 6 \cdot 7(2)$ & $89 \cdot 0 \pm 7.3(6)$ & 86 \\
\hline
\end{tabular}

* Each test was performed on decidual tissue pooled from a single female.

In outbred and A-strain mice the percentage of the total cells forming EA rosettes increased during the last part of gestation, reaching a very high proportion by Day 15 . There was a statistically significant increase in the percentage of rosetting cells between Days 14 and 15 in all except the allogeneically mated CBA mice $(P<0.02, P<0.05, P<0.001, P<0.05$ in outbred, CBA $\times$ CBA, $A \times A$ and $A \times C 57 B L$, respectively), and the increase between Days 13 and 14 was also significant in A-strain mice whether allogeneically $(P<0.05)$ or syngeneically $(P<0.01)$ mated. This pattern was not shown by the CBA mice for which there was no significant difference in the percentage of EA-RFC between any of the days except for syngeneic matings at Days 14 and $15(P<0.05)$.

No spontaneous rosette formation occurred after treatment with washed SRC, $\mathrm{F}\left(\mathrm{ab}^{\prime}\right)_{2^{-}}$ coated or IgM-coated SRC. Cells which formed rosettes with IgM and complement-coated iSRC were present in 13-15-day p.c. decidual cultures of A-strain mice (Table 4) but in smaller proportions than the EA-RFC found in the same females $(P<0.01$ for Day-15 cultures). $\mathrm{E}-\mathrm{IgM} / \mathrm{C}^{\prime} \mathrm{RFC}$ were not found in significant proportions at 10 days $p . c$.

Table 4. Proportion of cells forming EA and E-IgM-C' rosettes in cultures of decidual tissue from A-strain mice at Days 10-15 p.c.

\begin{tabular}{ccc}
\hline & \multicolumn{2}{c}{ Mean \pm s.d. \% of total cells forming rosettes } \\
\cline { 2 - 3 } Day $p . c$. & EA & E-IgM-C' \\
\hline 10 & $23 \cdot 0 \pm 14 \cdot 1$ & $1 \cdot 5 \pm 0.7$ \\
13 & $33 \cdot 0 \pm 12 \cdot 7$ & $11 \cdot 5 \pm 0 \cdot 7$ \\
14 & $61 \cdot 0 \pm 29 \cdot 4$ & $40 \cdot 3 \pm 22 \cdot 6$ \\
15 & $86 \cdot 8 \pm 5 \cdot 7$ & $50 \cdot 5 \pm 22 \cdot 5$ \\
\hline
\end{tabular}

\section{Discussion}

In this study of mice in early pregnancy, cells bearing receptors for the Fc region of immunoglobulin were identified in decidual tissue at all stages from Days 6 to 15 p.c., with their 
contribution to total cell numbers increasing as gestation proceeded. FcR-bearing cells were also identified in cultures of uterine cells from Days 3 to 5 p.c., before the development of the classic decidual response at the time of blastocyst implantation. A previous report (Bernard et al., 1978), also using an erythrocyte-antibody rosetting assay, described the presence of immunoglobulin-binding cells in suspensions of cells isolated from decidual tissue of mice at 7-9 days p.c. The present study has extended this observation to show that such cells are detectable in the tissue near the embryo before it implants and that they are still present after the establishment of the definitive placenta. In addition, the use of marker red cells coated with $\mathrm{F}\left(a b^{\prime}\right)_{2}$ fragment or the IgM fraction of the antiserum did not result in rosette formation by cultured uterine or decidual cells at any of the stages of pregnancy examined, thus indicating that the immunoglobulin binding is mediated by the Fc region of IgG and hence defining the receptors as Fc $\gamma$ receptors.

The decidual tissue is not a stable structure, but at each day of gestation has a different size and cellular form. At 4-5 days p.c., before a visible swelling is observed and before extensive differentiation of decidual cells is known to occur, large numbers of cells were obtained which grew readily in culture, but at 6 days p.c. significantly fewer cells grew and those that did were almost exclusively derived from the regions containing visible swellings. As the decidual swelling increased in size (Days 7 and 8 p.c.) the numbers of cells plating out also increased. It therefore seems likely that cultures of uteri and decidua from Day 6 and onwards do not contain the same cell types as cultures from 4 and 5 days p.c. The mean numbers of EA-RFC in cultures of 6-8 days p.c. were lower but less variable than in the earlier cultures, possibly indicating that the rosetting cells had a more stable structural role than merely being part of a cellular infiltrate as is perhaps likely at 4-5 days p.c. Leucocytic infiltration of the early implantation site in mice has been reported (Smith \& Wilson, 1974) and such infiltrating cells could be the source of the EA-RFC seen in the present study at 4 days p.c. Alternatively, some of the EA-RFC might be related to precursors of the granulated metrial gland cells (Smith, 1966; Stewart \& Peel, 1978).

The use of cultures of decidual cells which became confluent at some stages made the precise analysis of changes in the proportions of $\mathrm{Fc}$ receptor-bearing cells during the early stages of pregnancy impossible. However, this technique was chosen in preference to a suspension rosetting method in case the $\mathrm{Fc}$ receptors were destroyed by the trypsin used to disaggregate the cells, although a few tests carried out using a suspension rosetting assay on freshly prepared decidual cells suggested that at least some of the $\mathrm{Fc}$ receptor-bearing cells had trypsin-resistant Fc receptors.

There were considerable differences in the proportions of $\mathrm{Fc}$ receptor-bearing cells between the strains. In particular, CBA mice had very few round $\mathrm{Fc}$ receptor-bearing cells and most of the cells at the stages of gestation examined were flat in culture. Genotypic differences in the extent of the decidual cell reaction have been reported previously (Hetherington, 1971) and studies are in progress to examine histological differences between the decidual tissue of different strains. The variations seen within groups of animals of the same mating strain combination and gestational age could be explained by postulating a role for decidual $\mathrm{Fc}_{\mathrm{c}}$ receptor-bearing cells in defence against resorption, or possibly infection.

Although considerably more Fc receptor-bearing cells are found infiltrating the graft bed of an allogeneic than of a syngeneic skin graft (Dennison, Sandgren \& Clancy, 1977), the finding of such cells in deciduomata (Bernard et al., 1978) indicates that their presence is part of the differentiation in response to an original decidual stimulus and not solely the result of immunological challenge by the fetus. The results reported here support the claim by Bernard et al. (1978) that there is no significant difference in the decidual $\mathrm{Fc}$ receptor-bearing cell populations between allogeneically and syngeneically mated females.

Complement receptor-bearing cells were found in cultures of decidual tissue from mid-gestation pregnancies, but not in cultures of tissues from earlier in gestation. As judged by the proportions of these cells in the cultures, at least some of them must be on the same cells as 
the Fc receptors. Although Bernard et al. (1978) failed to detect complement receptors on 7-9-day p.c. cells in their study, they did not look at the later stages of pregnancy.

Bernard et al. (1978) reported that the EA-RFC had a diameter of 10-15 $\mu \mathrm{m}$, and were therefore larger than small lymphocytes and comparable to most of the true decidual cells formed by the differentiation of stromal fibroblasts. The EA-RFC found in the present experiments were also larger than small lymphocytes. On the basis of the compact shape of the rosettes and the increased numbers of round cells seen in wells of the same cells which were exposed only to unsensitized iSRC, the EA-RFC were identified as part of the population of round cells, and therefore different from the Ia-bearing cells described by Jenkinson \& Searle (1979) as flat dendritic cells. Although Bernard et al. (1978) postulated that the Fc receptor-bearing cells that they detected were genuine decidual cells derived from endometrial stromal fibroblasts, recent studies (R. F. Searle, unpublished observations) have shown that many of the round cells in cultures of Days-14-15 decidual tissue have characteristics, such as glass adherence, esterase staining and the ability to ingest yeast particles, which are associated with macrophage-like cells. However, it has been suggested that neither the Fc receptor-bearing cells nor the granulated cells in rat metrial gland derive from endometrial fibroblasts, but that small lymphocyte-like cells differentiate throughout the course of gestation to give rise to the granulated cells (Stewart \& Peel, 1977). The precise identity of these Fc receptor-bearing, macrophage-like cells in the decidual mass awaits further definition.

In CBA females the number of cells in the decidual cultures decreased over the period 11-15 days p.c. while the percentage of cells bearing Fc receptors remained fairly constant, but in A-strain and outbred females the number of cells increased from Days 13 to 15 p.c. concomitantly with an increase of $C^{\prime}$ receptor-bearing cells. This may indicate that $F c$ receptor-bearing cells migrate into this area at this stage of gestation. Since CBA mice have low fertility and a high resorption rate (Dillon, 1979; Clark, McDermott \& Szewczuk, 1980), the relative lack of $\mathrm{Fc}$ receptor-bearing cells in mid-gestation decidual tissue in this strain of mice may be a causative factor or a consequence of an inefficient reproductive process.

The finding of $\mathrm{Fc}$ and $\mathrm{C}^{\prime}$ receptor-bearing cells in decidual tissue strengthens the evidence supporting the hypothesis that the decidua has a role in maternal-fetal immunological interactions. Fc receptor-bearing lymphocytes have diverse roles in immunoregulation and it is tempting to suggest that cells with Fc receptors in the decidual tissue could also have immunoregulatory properties, perhaps involving enhancing antibodies or the release of suppressor substances, which might even include the Fc receptors themselves (Neauport-Sautes \& Rabourdin-Combe, 1979).

This work was carried out during the tenure of a Medical Research Council research studentship. I am grateful to Dr W. D. Billington for help and advice and to Miss V. Merry and Mrs V. Owen for efficient technical assistance.

\section{References}

Bar-Shavit, Z., Raz, A. \& Goldman, R. (1979) Comple ment and $\mathrm{Fc}$ receptor-mediated phagocytosis of normal and stimulated mouse peritoneal macrophages. Eur. J. Immunol. 9, 385-391.

Beer, A.E. \& Billingham, R.E. (1974) Host responses to intra-uterine tissue, cellular and foetal allografts. $J$. Reprod. Fert., Suppl. 21, 59-88.

Beer, A.E. \& Billingham, R.E. (1976) The Immunobiology of Mammalian Reproduction. Prentice-Hall, Inc., Englewood Cliffs.

Bernard, O., Scheid, M.P., Ripoche, M.A. \& Bennett, D. (1978) Immunological studies of mouse decidual cells. I. Membrane markers of decidual cells in the days after implantation. J. exp. Med. 148, 580-591.

Bray, J., Stewart, I. \& Craggs, R. (1978) The demonstration of cells bearing Fc receptors in the metrial gland of the pregnant rat uterus. Cell Tissue Res. 192, 89-96.

Clark, D.A., McDermott, M.R. \& Szewczuk, M.R. (1980) Impairment of host-versus-graft reaction in pregnant mice. II. Selective suppression of cytotoxic $\mathrm{T}$-cell generation correlates with soluble suppressor activity and with successful allogeneic pregnancy. Cell. Immunol. 52, 106-118. 
Dennison, D.K., Sandgren, J. \& Clancy, J. (1977) The level of $\mathrm{Fc}$ receptor leukocytes in primary and secondary skin allograft recipients. Transplantation 23, 479-484.

Dickler, H.B. (1976) Lymphocyte receptors for immunoglobulin. Adv. Immunol. 24, 167-214.

Dillon, K.J. (1979) Immunological studies on embryonic cell surface determinants. Ph.D. thesis, University of Bristol.

Elson, J., Jenkinson, E.J. \& Billington, W.D. (1975) Fc receptors on mouse placenta and yolk sac cells. Nature, Lond. 255, 412-414.

Finn, C.A. (1971) The biology of decidual cells. $A d v$. Reprod. Physiol. 5, 1-26.

Hetherington, C.M. (1971) The decidual cell reaction, placental weight, foetal weight and placental morphology in the mouse. J. Reprod. Fert. 25, 417-424.

Hetherington, C.M. \& Humber, D.P. (1975) The effects of active immunization on the decidual cell reaction and ectopic blastocyst development in mice. $J$. Reprod. Fert. 43, 333-336.

Jenkinson, E.J. \& Searle, R.F. (1979) Ia antigen expression on the developing mouse embryo and placenta. J. Reprod. Immunol. 1, 3-10.

Kerbel, R.S. Davies, A.J.S. (1974) The possible biological significance of $\mathrm{Fc}$ receptors on mammalian lymphocytes and tumour cells. Cell 3, 105-112.

La Via, M. \& La Via, D.S. (1978) Studies on Fc receptor function. I. IgG mediated inhibition of B lymphocyte activation by $\mathrm{T}$-dependent and $\mathrm{T}$-independent antigens. Cell. Immunol. 39, 297-306.

Masuda, T., Miyama, M., Kuribayashi, K., Yodoi, J., Takabayashi, A. \& Kyoizumi, S. (1978) Immunological properties of Fc receptors on lymphocytes. 5 . Suppressive regulation of humoral immune response by $\mathrm{Fc}$ receptor bearing $\mathrm{B}$ lymphocytes. Cell. Immunol. 39, 238-249.
McConnell, I. \& Lachmann, P.J. (1977) Complement receptors and cell associated complement components. In Immunology of Receptors, pp. 161-182. Ed. B. Cinader. Marcel Dekker Inc., New York.

Neauport-Sautes, C. \& Rabourdin-Combe, C. (1979) $\mathrm{T}$-cell hybrids bear Fc $\gamma$ receptors and secrete suppressor immunoglobulin binding factor. Nature, Lond. 277, 656-659.

Parish, C.R. \& Hayward, J.A. (1974) The lymphocyte surface I. Relationship between Fc receptors, C'3 receptors and surface immunoglobulin. Proc. $R$. Soc. $B$ 187, 47-63.

Ryan, J.L., Arbeit, R.D., Dickler, H.B. \& Henkart, P.A. (1975) Inhibition of lymphocyte mitogenesis by immobilized antigen-antibody complexes. $J$. exp. Med. 142, 814-826.

Smith, A.F. \& Wilson, I.B. (1974) Leucocytes in the luminal epithelium of the mouse uterus at implantation. J. Reprod. Fert. 38, 307-310.

Smith, L.J. (1966) Metrial gland and other glycogen containing cells in the mouse uterus following mating and through implantation of the embryo. Am. J. Anat. 119, 15-24.

Stewart, I. \& Peel, S. (1977) The structure and differentiation of granulated metrial gland cells of the pregnant mouse uterus. Cell Tissue Res. 184, $517-527$.

Stewart, I. \& Peel, S. (1978) The differentiation of the decidua and the distribution of metrial gland cells in the pregnant mouse uterus. Cell Tissue Res. 187, 167-179.

Yodoi, J., Takabayashi, A. \& Masuda, T. (1978) Immunological properties of $\mathrm{Fc}$ receptors on lymphocytes. 4. Fc receptor of Con A induced suppressor and helper T. Cells. Cell. Immunol. 39, 225-237. 